\title{
Causal attributions for success and failure among athletes: Validation of the Croatian version of the revised Causal dimension scale (CDS-II)
}

Rebeka Prosoli $^{1 \mathrm{ABD}}$, Benjamin Banai ${ }^{2 \mathrm{CD}}$, Renata Barićc ${ }^{3 \mathrm{AD}}$, Marc Lochbaum ${ }^{4,5 \mathrm{CDE}}$, Sydney Cooper ${ }^{6 \mathrm{CD}}$, Margareta Jelićc ${ }^{7 \mathrm{~A}}$

${ }^{1}$ Faculty of Kinesiology, University of Zagreb, Croatia

${ }^{2}$ Banai Analitika, Croatia

${ }^{3}$ Faculty of Kinesiology, University of Zagreb, Croatia

${ }^{4}$ Department of Kinesiology and Sport Management, Texas Tech University, USA

${ }^{5}$ Education Academy, Vytautas Magnus University, Lithuania

${ }^{6}$ Honors College, Texas Tech University, USA

${ }^{7}$ Faculty of Humanities and Social Sciences, University of Zagreb, Croatia

Authors' Contribution: A - Study design; B - Data collection; C - Statistical analysis; D - Manuscript Preparation; E - Funds Collection.

\section{Abstract \\ Background \\ and Study Aim}

Material and

Methods

Results

Conclusions: We confirmed that the Croatian version of the CDS-II has adequate psychometric properties and is therefore suitable for research in sport situations.

Keywords:

Researchers since the late 1970s have been interested in finding out the reasons attributed to outcomes. To facilitate attribution research in Croatia we translated and validated The Revised Causal Dimension Scale (CDS-II) and examined its invariance when attributing most and least successful competition performances.

To achieve our stated aim, 384 kinesiology students completed the translated CDS-II. To test the latent structure of the questionnaire, we used CFA and tested two alternative models (orthogonal solution and model with correlated latent variables). Additionally, we examined the CDS-II invariance when attributing the most and the least successful competition performance in sport using longitudinal CFA. The reliability was tested using Cronbach alpha coefficients. Lastly, we tested differences in latent means between most and least successful performance using pairwise t-test.

Similar to the originally published findings, CFA indicated the CDS-II structure with correlated latent variables had an adequate and better fit than the orthogonal solution in both situations. Furthermore, we confirmed configural, metric and scalar invariance, as well as partial strict invariance since one item's residuals differed significantly from the others. Cronbach alpha coefficients were adequate across both situations. Lastly, athletes attributed their most successful performances to more internal, stable and controllable reasons than their least successful performances.

reasons, achievement, competition, performance, causal attributions

\section{Introduction}

In life, we face many outcomes. When we do, we are usually interested in finding the reasons behind the outcomes so that we can influence similar situations in our future [1]. Attribution theory explains the process of how we try to explain reasons behind different life outcomes [2].

Kelley and Michela [3] described an attribution process as follows: we can recognize antecedents (beliefs, information, and motivation), attributions (perceived cause) and consequences (expectations, emotions, and behaviour). Weiner [1, 4] developed a model considering all three components of this model in which he claimed that causes behind the behaviour can be placed on three dimensions: (1) locus which locates from where the cause is coming from (inside or outside the person), (2) stability which defines causes on a stable or unstable continuum, and (3) controllability which describes perceived level of

\footnotetext{
(c) Rebeka Prosoli, Benjamin Banai, Renata Barić, Marc Lochbaum, Sydney Cooper, Margareta Jelić, 2021 doi:10.15561/26649837.2021.0406
}

control over the cause (controllable vs. uncontrollable). Weiner [1, 4] suggested that interpretation of the causes behind the behaviour can vary over time, from situation to situation, and from person to person, but the dimensions are invariant. Therefore, it is essential to find a way of measuring attribution dimensions.

Over the years researchers developed different methods to measure attribution dimensions. In traditional approaches, researchers [5] placed the causal attributions made by participants on the attribution dimensions, thus making what Russel [6] named "fundamental attribution researcher error". This error represents the idea that the author of the research perceives the causes in the same way as the participant who made them. Weiner [1] in his theory suggests that attributions represent the perception of the person who is making them. Therefore, the above-mentioned way of coding attributions may not be appropriate. The solution was to develop a methodology in which participants themselves place the reasons on the attribution dimensions. Russell [6] developed the CDS (Causal Dimension Scale) to measure participant's 
perception on how causes are placed on three attribution dimensions: locus, stability and controllability. This questionnaire was used in numerous studies [7 - 9] and although Russell and colleagues [10] confirmed the psychometric properties of the scale, studies also reported inconsistent reliability and validity results. The most worrisome subscale being the controllability one as low levels of internal consistency has been reported, as well as the high correlations between controllability and locus subscale $[9,10])$. Also, the original control subscale in CDS offered bipolar answers from "controllable by you or other people" to "uncontrollable by you or other people" which means participants could only place the cause as controllable or uncontrollable [6]. However, McAuley and his colleagues [11] suggested that participants could view outcome as both controllable or uncontrollable by the person and controllable or uncontrollable by other people. As an answer to the problems with controllability subscale, McAuley et al. [11] suggested that this dimension should be divided into two separate subscales (a) personal control and (b) external control therefore creating the Revised Causal Dimension Scale (CDS-II).

The authors of the CDS-II questionnaire pointed out adequate levels of internal consistency with confirmed factorial structure in laboratory settings, real sport competition, physical and motor skills, and academic situations [11]. The adequate levels of internal consistency for all subscales as well as confirmation of the original four factor structure of the CDS-II were also reported [12]. However, Watkins and Cheng [13], in their study with Hong Kong students attributing their academic test performance, reported concerns about reliability of the external control subscale. Also, they concluded that there was extensive overlap between personal control and locus of causality subscales. This extensive overlap resulted in their confirmatory factor analysis suggesting the best fit for the three-factor solution: stability, external control and locus plus personal control. Watkins et al. [14] found the same overlap on Nepalese students attributing their academic test performances with the best fit for success outcomes again being those same three factors: external control, stability and locus plus personal control. Furthermore, they found that none of the models investigated in their study offered the adequate fit for failure outcomes as well as all subscales having barely adequate internal consistency. Crocker and colleagues [15] in their study reported that the four-factor oblique model suggested by McAuley et al. [11] provided an acceptable fit for the adolescent athletes involved in team sports. However, the fit for the athletes involved in individual sport showed some concerns, especially around the changeable-unchangeable stability item (item 11) which was problematic in the team sample and in the gender invariance analysis. Poor reliability was also found in a study [16] but this time for the stability subscale while the other subscales were all highly reliable. Taken together, the findings suggest there still is a need for further studies testing the psychometric properties of CDS-II questionnaire.
Considering the importance of investigating attributions, the first step is to have appropriate questionnaires with adequate psychometric properties. Previous researchers in the field [14] implied that further studies should test the validity of the CDS-II as well as the underlying model of attributions for success and failure outcomes. Given that the CDS-II questionnaire is dominantly used measure of state casual attributions even in the relatively recent studies $[17,18]$ which has not yet been translated to Croatian, as well as mixed results of the previous studies concerning psychometric properties, an extensive study is needed to facilitate attribution research in Croatia. Since there is an evident lack of attribution questionnaires in Croatian language, the aim of this study was to validate the Croatian version of the CDSII questionnaire as well as to investigate differences in attribution for the most and least successful performances of Croatian athletes.

\section{Material and Methods}

Participants

The 384 athletes participated in this study. Their mean age was 20.43 years $(S D=1.03)$ and there were more male $(60.4 \%)$ than female $(39.6 \%)$ participants. All participants were kinesiology students who reported practicing different team (62.83\%; e.g. soccer, handball, volleyball, basketball) and individual $(37.17 \%$; e.g. swimming, tennis, gymnastics) sports at some point in their life at regional $(13.46 \%)$, national $(36.68 \%)$ or international levels (49.86\%). 45.8\% participants reported still being actively involved in competitive sport at the time research was conducted.

\section{Instruments.}

Causal attributions. The CDS-II is a 12-item measure consisting of four subscales (3 items each): locus of causality, stability, external control and personal control [11]. The items are rated on a bipolar scale ranging from 1 to 9 . The higher results represent more internal, stable, personally and externally controllable attributions. For the original version, authors of the CDSII scale reported alpha reliability of .67 for locus and stability subscales, .79 for personal control and .82 for external control [11]. In this study the CDS-II Croatian translated questionnaire was used twice: once for the most successful competition performance and once for the least successful competition performance. The direction at the beginning of the questionnaire was: "Please try to remember the competition in which you had your least successful performance. In the space below, please enter what you think is the main reason for your failure in this competition." for the least successful performance. In the most successful performance condition, the parts of the sentence mentioning failure were replaced with those mentioning success. After writing the main reason on the designated place, participants were instructed to fill the questionnaire keeping this reason in mind.

\section{Procedure}

CDS-II was translated to Croatian using back translation procedure. Both translators agreed that 
the second translation matched the original message and no meaningful differences between the two were present. Following the institutional ethical approval, the participants were approached after their lecture at their university. They were informed about the withdrawal procedure and asked to sign the informed consent form before completing the questionnaire.

Statistical Analysis.

To test the latent structure of the questionnaire, we used CFA and tested two alternative models (orthogonal solution and model with correlated latent variables). Additionally, we examined the CDS-II invariance when attributing the most and the least successful competition performance in sport using longitudinal CFA. The reliability was tested using Cronbach alpha coefficients. Lastly, we tested differences in latent means between most and least successful performance using pairwise t-test.

\section{Results}

Descriptive statistics

All analyses were conducted using a programming language for statistical computing $R$ v.3.6.0 [19], using packages psych v1.9.12.31 [20] and lavaan v.0.6-5 [21]. In Table 1 we present descriptive statistics for individual items of CDS-II scale, both in the context of remembering the most and the least successful sport performance. Values of skewness (all $S I<3$ ) and kurtosis indices (all $K I<8$ ) indicate that the distributions of observed data do not deviate from the theoretical normal distributions [22]. Furthermore, we examined Mardia multivariate skewness and kurtosis indices, which indicated that multivariate normality was not met in both most successful (MS $=1006.99, p<0.01 ; M K=19.40, p<0.01)$, and least successful $(M S=986.54, \mathrm{p}<0.01, M K=16.24, p<0.01)$ performances' evaluations.

Before testing latent structure of CDS-II, we calculated Pearson product-moment correlations which are presented in Table 2. These correlations were further used to test the latent structure of Croatian translation of the questionnaire.

Confirmatory factor analysis

To test whether the latent structure of Croatian translation of CDS-II is the same as the original English version we applied confirmatory factor analysis (CFA). We tested two alternative models described by McAuley et al. [11] with four latent variables: locus of causality, stability, personal control and external control. In one model we tested an orthogonal solution, and in another, presented in Figure 1, we allowed latent variables to be correlated. Both models were examined for the attributions of the most and the least successful performance.

All models were estimated using maximum likelihood estimation with robust standard errors and a Satorra and Bentler [23] scaled test statistic, and alternative models were compared using scaled difference chi square test [23]. Moreover, model fit for each iteration was evaluated using root mean square error of approximation together with its 95\% confidence intervals (RMSEA) [24], standardized root mean residual (SRMR) [25], TuckerLewis index (TLI) [26] and comparative fit index (CFA) [25]. An adequate model fit is characterized with low $\chi^{2}$ (ideally insignificant, albeit it is heavily influenced by the sample size), RMSEA $(<.06)$ and SRMR $(<.06)$ and high values of TLI and CFI $(>.95)$. Fit indices from all of four tested CFA models are presented in Table 5.

It has been shown that a model with correlated

Table 1. Descriptive statistics of results on individual CDS-II items obtained when remembering the most and the least successful sport performance

\section{Sport Performance}

\begin{tabular}{lllllllllll}
\hline \multicolumn{3}{l}{ Most successful } & \multicolumn{7}{c}{ Least successful } \\
\hline Item & $M$ & $S D$ & $S I$ & $K I$ & $S E$ & $M$ & $S D$ & $S I$ & $K I$ & $S E$ \\
\hline 1 & 6.2 & 2.2 & -0.62 & -0.42 & 0.11 & 5.0 & 2.8 & -0.02 & -1.42 & 0.14 \\
2 & 6.6 & 2.0 & -0.73 & -0.21 & 0.10 & 5.1 & 2.5 & -0.08 & -1.14 & 0.13 \\
3 & 5.8 & 2.1 & -0.33 & -0.66 & 0.11 & 3.5 & 2.2 & 0.51 & -0.68 & 0.11 \\
4 & 6.4 & 1.9 & -0.57 & -0.21 & 0.10 & 5.5 & 2.4 & -0.22 & -1.03 & 0.12 \\
5 & 4.2 & 2.3 & 0.16 & -1.12 & 0.12 & 4.0 & 2.4 & 0.31 & -0.97 & 0.12 \\
6 & 7.1 & 1.7 & -0.93 & 0.69 & 0.09 & 5.9 & 2.4 & -0.49 & -0.66 & 0.12 \\
7 & 5.2 & 2.2 & -0.09 & -0.70 & 0.11 & 3.7 & 1.9 & 0.22 & -0.60 & 0.10 \\
8 & 4.6 & 2.3 & -0.04 & -1.14 & 0.12 & 4.4 & 2.4 & 0.13 & -1.14 & 0.12 \\
9 & 7.2 & 1.7 & -1.04 & 1.09 & 0.08 & 6.4 & 2.2 & -0.74 & -0.31 & 0.11 \\
10 & 6.9 & 1.9 & -0.95 & 0.25 & 0.10 & 5.9 & 2.4 & -0.43 & -0.89 & 0.12 \\
11 & 4.4 & 2.2 & 0.11 & -0.79 & 0.11 & 3.2 & 2.1 & 0.72 & -0.25 & 0.11 \\
12 & 4.3 & 2.2 & 0.00 & -1.00 & 0.11 & 4.2 & 2.4 & 0.21 & -0.98 & 0.12
\end{tabular}

Note: $M=$ mean; $S D$ = standard deviation; $S I$ = skewness index; $K I=$ kurtosis index; $S E$ = standard error of the mean 
Table 2. Pearson correlation coefficients between CDS-II items

\begin{tabular}{|c|c|c|c|c|c|c|c|c|c|c|c|c|}
\hline Item & 1 & 2 & 3 & 4 & 5 & 6 & 7 & 8 & 9 & 10 & 11 & 12 \\
\hline 1 & & $0.35^{*}$ & $0.24 *$ & $0.29 *$ & $-0.14^{*}$ & $0.52 *$ & $0.21^{*}$ & $-0.16^{*}$ & $0.41 *$ & $0.29 *$ & 0.02 & $-0.15^{*}$ \\
\hline 2 & $0.44 *$ & & -0.06 & $0.78^{*}$ & $-0.15^{*}$ & $0.31^{*}$ & $0.10^{* *}$ & $-0.13^{*}$ & $0.23 *$ & $0.66^{*}$ & $-0.11^{* *}$ & $-0.16^{*}$ \\
\hline 3 & $0.40 *$ & $0.37^{*}$ & & $-0.13^{* *}$ & 0.05 & $0.14^{*}$ & $0.46^{*}$ & $0.10 * *$ & $0.12^{* *}$ & -0.05 & $0.49 *$ & $0.14 *$ \\
\hline 4 & $0.38 *$ & $0.75^{*}$ & $0.50 *$ & & -0.09 & $0.23 *$ & 0.08 & -0.08 & $0.22 *$ & 0.69 & $-0.19 *$ & $-0.11 * *$ \\
\hline 5 & $-0.29 *$ & $-0.22^{*}$ & $-0.14^{*}$ & $-0.26^{*}$ & & $-0.20 *$ & 0.03 & $0.70 *$ & $-0.30 *$ & -0.05 & $0.13 * *$ & 0.65 \\
\hline 6 & $0.52 *$ & $0.46^{*}$ & $0.33 *$ & $0.43 *$ & $-0.28 *$ & & $0.16^{*}$ & $-0.20^{*}$ & $0.64 *$ & $0.30^{*}$ & 0.08 & $-0.23 *$ \\
\hline 7 & $0.36^{*}$ & $0.30^{*}$ & $0.48^{*}$ & $0.31 *$ & $-0.11 * *$ & $0.29 *$ & & 0.07 & $0.10 * *$ & 0.05 & $0.36^{*}$ & 0.06 \\
\hline 8 & $-0.35 *$ & $-0.23 *$ & $-0.25^{*}$ & $-0.24 *$ & $0.70^{*}$ & $-0.21 *$ & $-0.16^{*}$ & & $-0.33^{*}$ & -0.06 & $0.12^{* *}$ & $0.74 *$ \\
\hline 9 & $0.45^{*}$ & $0.37^{*}$ & $0.23 *$ & $0.38 *$ & $-0.32 *$ & $0.50^{*}$ & $0.20 *$ & $-0.30^{*}$ & & $0.33^{*}$ & -0.02 & $-0.29 *$ \\
\hline 10 & $0.33^{*}$ & $0.62 *$ & $0.36^{*}$ & $0.65^{*}$ & $-0.19^{*}$ & $0.41^{*}$ & $0.29 *$ & $-0.18^{*}$ & $0.40 *$ & & $-0.20^{*}$ & -0.06 \\
\hline 11 & $0.23 *$ & $0.14^{*}$ & $0.41^{*}$ & $0.20 *$ & 0.00 & $0.18^{*}$ & $0.47^{*}$ & -0.10 & $0.13^{* *}$ & 0.09 & & 0.18 \\
\hline 12 & $-0.24 *$ & $-0.12^{* *}$ & $-0.16^{*}$ & $-0.13 * *$ & $0.61^{*}$ & $-0.16^{*}$ & -0.07 & $0.67^{*}$ & $-0.25^{*}$ & $-0.11 * *$ & -0.01 & \\
\hline
\end{tabular}

Note: ${ }^{*} p<0.05 ;{ }^{*} p<0.01$; Note: Values below the diagonal refer to attributions related to the most successful performance, while the values above the diagonal refer to attributions related to the least successful performance.

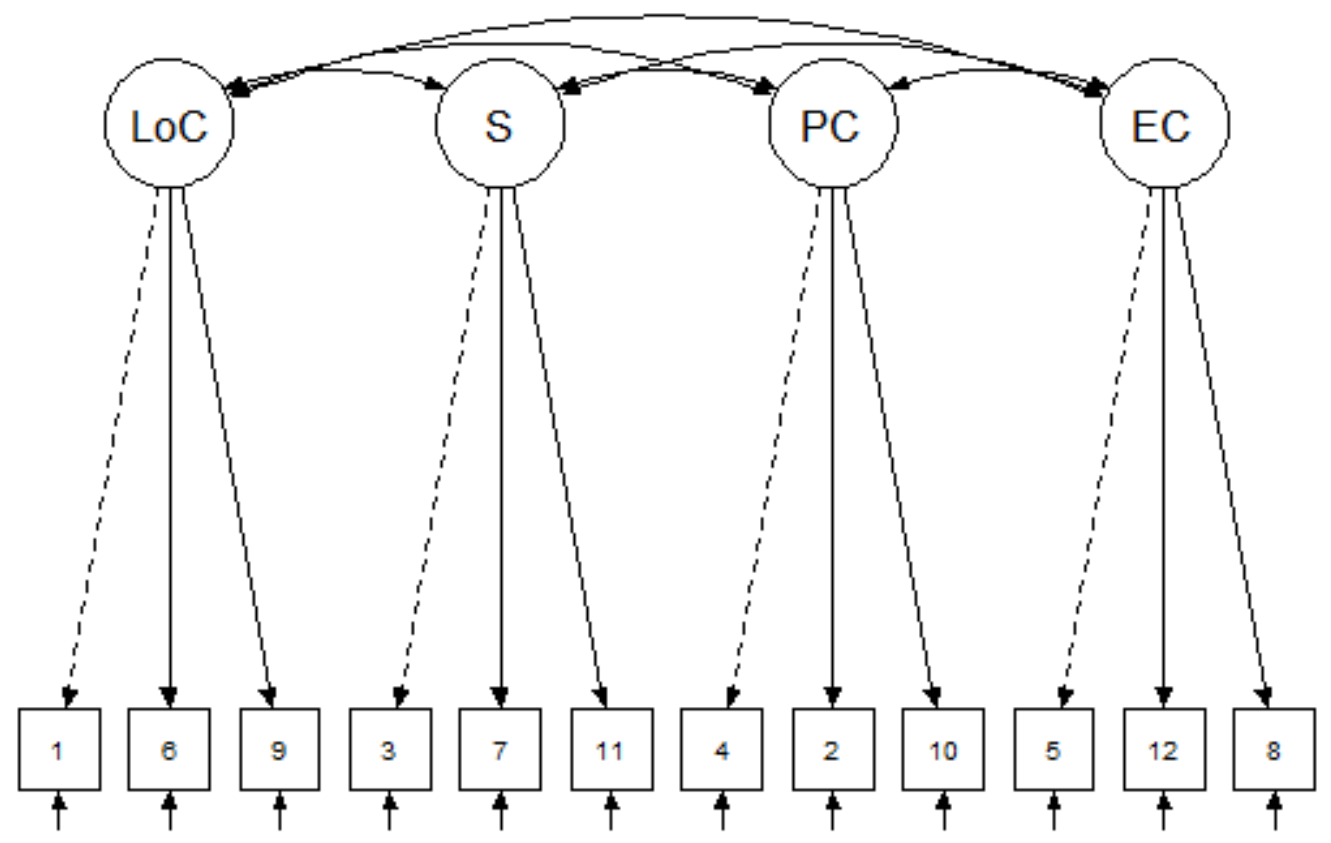

Figure 1. Model specification of CDS-II structure [11], with correlated latent variables. Numbers in manifest variables boxes represent item number; LoC- Locus of Causality; S- Stability, PC- Personal control; EC- External control.

latent variables showed a significantly better fit both when participants attributed the most successful sport performance $\left(\Delta \chi^{2}=255.12, d f=6, p<0.01\right)$, and the least successful sport performance $\left(\Delta \chi^{2}=96.714, \mathrm{df}=6\right.$, $\mathrm{p}<0.01)$. Fit indices indicated a good fit for the model of attributions of the most successful sport performance, and good to moderate fit for the model of attributions of the least successful sport performance. For both models, all items had high loadings $(\geq .56,[22,27])$ with their hypothesized latent variables (Table 3). Correlations between factors are presented in Table 4.

Testing for measurement invariance

Next, we examined if CDS-II measures the same constructs for both attributing the most and the least successful sport performance. For that we tested measurement invariance using longitudinal CFA following steps described in Brown [28], and we used Cheung and Rensvold's [29] recommendations for dealing with partial 
invariance. First, we tested for configural invariance, a test of the same item configurations for attributions of different events. This model is tested by specifying the same model on two occasions, leaving all loadings and intercepts to vary freely. If fit indices indicate a good fit for configural invariance, then it is possible to conclude that the latent structure of the measure is the same in two instances. Next, we examined metric invariance, which examines if factor loadings are the same across two measurements. Third, we tested for scalar invariance by constraining item intercepts to be equal across two measurements. Lastly, we examined a strict invariance by forcing error variance to be equal. Differences between successive models were assessed by $\triangle \mathrm{CFI}$, for which a change of CFI between models less than 0.01 indicate that the invariance is established, while values greater than 0.01 indicate that examination of partial invariance is needed. Finally, all fit indices and model comparisons are presented in Table 5.

Test for configural invariance showed a good fit $\left(\chi^{2}\right.$ $=379.65, d f=212, p<0.01 ; \operatorname{RMSEA}[90 \% \mathrm{CI}]=0.049$
$[0.041,0.056] ; \mathrm{SRMR}=0.051 ; \mathrm{TLI}=0.938 ; \mathrm{CFI}=0.950$ ) indicating the same item configuration in attributing the most and the least successful sport performance. Furthermore, next steps indicated that metric ( $\triangle \mathrm{CFI}$ $=0.003)$ and scalar $(\Delta \mathrm{CFI}=0.007)$ invariances are established. However, testing for strict invariance indicated that residuals in both models differ significantly $(\Delta \mathrm{CFI}=0.013)$. To explore this difference, we relaxed constraints of equal residuals for each item at the time to test for partial strict invariance. It has been shown that Item 1 had greater variance in attributing the least successful $(4.89,[S E=0.432])$ than the most successful sport performance $(2.53,[S E=0.274])$. After accounting for this difference partial strict invariance was established $(\Delta \mathrm{CFI}=0.006)$.

Reliabilities and differences in latent means

Cronbach alpha reliability coefficients were calculated for all three-item scales for attributions of different sport performances. Reliabilities for attributions of the most successful sport performance were adequate (locus of causality, $\alpha=.73$; stability, $\alpha=.70$ ), to good (personal

Table 3. Factor loadings of Croatian CDS-II items in orthogonal and oblique models for attributions of the most and the least successful sport performance

\begin{tabular}{|c|c|c|c|c|c|}
\hline \multirow[b]{3}{*}{ Factor } & \multirow[b]{3}{*}{ Item } & \multicolumn{4}{|c|}{ Sport Performance } \\
\hline & & \multicolumn{2}{|c|}{ Most successful } & \multicolumn{2}{|c|}{ Least successful } \\
\hline & & Orthogonal & Oblique & Orthogonal & Oblique \\
\hline \multirow[t]{3}{*}{ Locus of causality } & 1 & .68 & .72 & .57 & .62 \\
\hline & 6 & .76 & .72 & .90 & .83 \\
\hline & 9 & .66 & .65 & .71 & .76 \\
\hline \multirow[t]{3}{*}{ Stability } & 3 & .64 & .75 & .80 & .81 \\
\hline & 7 & .74 & .69 & .57 & .56 \\
\hline & 11 & .63 & .56 & .61 & .61 \\
\hline \multirow[t]{3}{*}{ Personal control } & 2 & .88 & .88 & .91 & .89 \\
\hline & 4 & .85 & .85 & .86 & .87 \\
\hline & 10 & .73 & .74 & .77 & .78 \\
\hline \multirow[t]{3}{*}{ External control } & 5 & .80 & .81 & .79 & .79 \\
\hline & 8 & .77 & .76 & .83 & .84 \\
\hline & 12 & .87 & .87 & .90 & .89 \\
\hline
\end{tabular}

Table 4. Correlations between factors

\begin{tabular}{lllll}
\hline & Locus of causality & Stability & Personal control & External control \\
\hline Locus of causality & & $.23^{* *}$ & $.41^{* *}$ & $-.35^{* *}$ \\
Stability & $.59 * *$ & -.12 & $.17^{*}$ \\
Personal control & $.69 * *$ & $.57^{* *}$ & & $-.15^{*}$ \\
External control & $-.47^{* *}$ & $-.25^{* *}$ & $-.29 * *$ &
\end{tabular}

Note: ${ }^{* *} p<0.01 ;{ }^{*} p<0.05$; Values below the diagonal refer to attributions related to the most successful performance, while the values above the diagonal refer to attributions related to the least successful performance. 
Table 5. Fit indices for CFA and measurement invariance models

\begin{tabular}{lllllllll}
\hline CFA model & $\mathbf{X}^{2}$ & df & RMSEA & $\mathbf{9 0 \% ~ C l}$ & SRMR & TLI & CFI & \multicolumn{1}{c}{ CCFI } \\
\hline $\begin{array}{l}\text { Most successful } \\
\text { (orthogonal) }\end{array}$ & 368.49 & 54 & .123 & {$[.113, .135]$} & .231 & .747 & .802 & \\
Most successful (oblimin) & 114.78 & 48 & .060 & {$[.047, .073]$} & .050 & .940 & .956 & \\
$\begin{array}{l}\text { Least successful } \\
\text { (orthogonal) }\end{array}$ & 236.48 & 54 & .094 & {$[.083, .106]$} & .151 & .863 & .888 & \\
Least successful (oblimin) & 133.26 & 48 & .068 & {$[.056, .081]$} & .060 & .932 & .950 & \\
Configural & 379.65 & 212 & .049 & {$[.041, .056]$} & .051 & .938 & .950 & \\
Metric & $399-36$ & 220 & .049 & {$[.042, .057]$} & .055 & .936 & .947 & .003 \\
Scalar & 431.75 & 228 & .051 & {$[.044, .059]$} & .054 & .930 & .940 & .007 \\
Strict & 621.59 & 241 & .070 & {$[.064, .077]$} & .065 & .869 & .887 & .013 \\
Partial strict & 461.93 & 239 & .053 & {$[.046, .060]$} & .056 & .926 & .934 & .006 \\
\hline
\end{tabular}

control, $\alpha=.88$, external control, $\alpha=.88$ ), according to interpretative guidelines [30]. Similarly, adequate (locus of causality, $\alpha=.76$; stability, $\alpha=.70$ ) to good (personal control, $\alpha=.88$, external control, $\alpha=.88$ ) reliability coefficients were found for attributions of the least successful sport performance.

Finally, we calculated latent means based on a partial strict invariance model and compared differences in attributions between the most and the least successful sport performances using pairwise t-test. Locus of causality was higher $(t(378)=11.02, p<0.01, d=0.57)$ while remembering the most successful $(M=6.19, S D=$ 1.22) compared to least successful sport performance ( $M$ $=5.02, S D=1.85)$ with moderate effect size. Stability was higher $(t(378)=18.06, p<0.01, d=0.92)$ while remembering the most successful $(M=5.73, S D=1.59)$ compared to least successful sport performance $(M=$ $3.53, S D=1.55)$ with large effect size. Next, personal control was higher $(t(378)=10.21, p<0.01, d=0.52)$ while remembering the most successful $(M=6.49, S D$ $=1.49$ ) compared to least successful sport performance $(M=5.33, S D=2.01)$ with moderate effect size. Lastly, statistically significant difference was not found $(t(378)=$ $1.44, p>0.05, d=0.07$ ) between attributions of external control while remembering the most $(M=4.18, S D=$ $1.67)$ and the least successful sport performance $(M=$ 4.04, $S D=1.82$ ).

\section{Discussion}

One of the aims of this study was to test whether the latent structure of Croatian translation of the CDS-II questionnaire is the same as the original version. To test that we applied confirmatory factor analysis (CFA) and tested two alternative models (orthogonal and correlated solution) which were described by McAuley et al. [11] in their original study. The results suggested that the model with correlated latent variables showed a better fit both in most and least successful competition performance situations. In that model, fit indices showed good fit for the most successful competition performance and good to moderate fit for the least successful competition performance. For both models in both situations all items had high loadings with their hypothesized latent variables. From these results it can be concluded that Croatian version of the CDS-II [11] showed satisfactory construct validity and therefore can be considered appropriate to use in future studies. However, we have to notice that the fit indexes in the least successful situation indicate somewhat poorer fit, so we suggest that in the future studies researches could consider formulating the question about the least successful competition performance differently. When the athletes are asked about their least successful competition performance maybe they have different ideas about what that really is as compared to asking them, for example, about their worst competition performance. The same could be done for the most successful performance. Furthermore, high correlations between factors in CDS-II questionnaire was one of the concerns reported in a study conducted by Crocker et al. [15] on adolescent athletes, especially the high correlation $(>.80)$ between locus and personal control subscales. In our study, correlation between locus and personal control was .69 in the most successful performance situation which is similar but slightly lower than the correlation reported in original study (.71) conducted by McAuley et al. [11].

Second aim of this study was to examine if Croatian version of the CDS-II questionnaire measures the same construct in both most and least successful competition performance situations. In order to do that, we used longitudinal CFA to test measurement invariance. Results show that the test for configural invariance showed a good fit which means there is the same item configuration when attributing most and least successful competition performance. Also, metric and scalar invariances were established. However, when testing for strict invariance the residuals in both models differ significantly, so we 
tested for partial strict invariance. When accounting for the greater variance of Item 1 in the least successful performance compared to the most successful performance, partial strict invariance was established. In general, it can be concluded that the strict invariance is not achieved since residuals are different on the first item where athletes have a wider range of the answers when attributing the least successful performances. In other words, there is an evident problem with calculating arithmetic mean on the locus of causality subscale because variances of the first item are not equal in both situations. This means we are bringing an error when calculating arithmetic mean from the start. However, since we achieved scalar invariance, we have a right to compare latent means [31]. Therefore, we suggest that, in those two contexts, attributions should be compared by using latent means.

Following that suggestion, we calculated latent means based on a partial strict invariance model and compared differences in making attributions for the most and least successful sport competition performance using pairwise t-test. The results indicated that athletes in our study made more internal, stable and personally controllable attributions for the most successful sport competition performance compared to the least successful one with no significant difference on external control subscale. This is in line with previous study conducted by Hamilton and Jordan [32] which reported results in the same direction. On the other hand, Santamaria and Furst [33] found the significant differences in the same direction as the ones found in our study but only for the locus and personal control subscales. In line with our findings was also the study conducted by Russell [6] who found that success in different achievement situations was attributed to more internal, stable and controllable causes than failure. Furthermore, some studies found that winners in sport tend to make more internal, stable and controllable attributions than losers [9, 34] while others found the differences in the same direction but only on the stability and controllability dimensions [8]. However, De Michele et al. [35] reported that winners in wrestling made more internal, stable, personally and externally controllable reasons compared to losers. Our results on athletes from different sports and different levels of participation can contribute to further understanding the differences in attributing success and failure in sport.

Finally, the reliability coefficients obtained in this study are somewhat low (locus success.73; locus failure .76 ; stability success .70; stability failure .70; personal control success .88; personal control failure .88; external control success .88; external control failure .88). However, we can attribute that to the fact that each subscale in the CDS-II questionnaire has only 3 items. On the other hand, the reliability indexes in this study are higher than those in the original study (locus .67; stability .67; personal control .79; external control .82) conducted by McAuley et al. [11] and also mostly higher than those obtained in the study conducted by Watkins and Cheng [13] (locus .72; stability .71; personal control .76; external control .57) and Dong et al. [17] (locus .76; stability .66; personal control .83; external control .70).

As any other research, this one as well has some areas which should be improved in future studies. One of such areas is the order of situations. In this study all the athletes filled the attribution questionnaire regarding the most successful competition performance first, and then they filled the questionnaire regarding their least successful competition performance. We suggest that future studies rotate the order of the questionnaires. Furthermore, current study didn't examine gender or type of sport invariances which were addressed as problematic in previous studies [15]. Future studies could focus on further investigating those concerns.

\section{Conclusions}

In general, it can be concluded that Croatian version of the CDS-II [11] in this study showed satisfactory construct validity and therefore can be considered appropriate to use in future studies. Also, the reliability indexes of the subscales were adequate to good. Furthermore, from the longitudinal CFA it can be concluded that CDSII questionnaire measures the same construct when examining attributions for the most and least successful sport performances. When comparing the two situations using pairwise t-test and latent means the results indicated that athletes in this study made more internal, stable and personally controllable attributions for their most successful competition performance compared to the least successful one.

\section{References}

1. Weiner B.AnAttributional Theory of Achievement Motivation and Emotion. Psychological Review. 1985;2(4):548-573. https://doi.org/10.1037/0033-295X.92.4.548

2. Aronson E, Wilson, TD, Akert RM, Sommers SR. Social psychology (Social perception: How we come to understand other people, p. 84-118). $9^{\text {th }}$ ed. London, England: Pearson Education; 2015.

3. Kelley HH, Michella JL. Attribution Theory and Research. Annual Review of Psychology. 1980;31:457-501. https://doi.org/10.1146/annurev.ps.31.020180.002325

4. Weiner B. A theory of motivation for some classroom experiences. Journal of Educational Psychology. 1979;71(1):3-25. https://doi.org/10.1037/0022-0663.71.1.3

5. Lau RR, Russell D. Attributions in the sports pages. Journal of Personality and Social Psychology. 1980;39(1):29-38. https://doi.org/10.1037/0022-3514.39.1.29

6. Russell D. The Causal Dimension Scale: A measure of how individuals perceive causes. Journal of Personality and Social Psychology. 1982;42(6):1137-1145. https://doi.org/10.1037/0022-3514.42.6.1137

7. Abraham IL. Causal attributions of depression: Reliability of the "Causal Dimension Scale" in research on clinical inference. Psychological Reports. 1985;56(2):415-418. https://doi.org/10.2466/pr0.1985.56.2.415

8. Mark MM, Mutrie N, Brooks DR, Harris DV. Causal attributions of winners and losers in individual competitive 
sports: toward a reformulation of the self-serving bias. Journal of Sport Psychology. 1984;6(2):184-196. https://doi.org/10.1123/jsp.6.2.184

9. McAuley E, Gross JB. Perceptions of causality in sport: An application of the Causal Dimension Scale. Journal of Sport Psychology. 1983;5(1):72-76. https://doi.org/10.1123/jsp.5.1.72

10.Russell DW, McAuley E, Tarico V. Measuring causal attributions for success and failure: A comparison of methodologies for assessing causal dimensions. Journal of Personality and Social Psychology. 1987;52(6):1248-1257. https://doi.org/10.1037/0022-3514.52.6.1248

11.McAuley E, Duncan TE, Russell DW. Measuring causal attributions: The revised causal dimension scale (CDS-II). Personality and Social Psychology Bulletin. 1992;18(5):566-573. https://doi.org/10.1177/0146167292185006

12.Cortés-Suárez G, Sandiford JR. Causal attributions for success or failure of students in college algebra. Community College Journal of Research and Practice. 2008;32(4-6):325-346. https://doi.org/10.1080/10668920701884414

13. Watkins D, Cheng C. The revised Causal Dimension Scale: a confirmatory factor analysis with Hong Kong students. British Journal of Educational Psychology. 1995;65(2):249-252. https://doi.org/10.1111/j.2044-8279.1995.tb01146.x

14. Watkins D, Sachs J, Regmi M. Confirmatory factor analysis of the revised Causal Dimension Scale: a Nepalese investigation. Psychological Reports. 1997;81(3):963-967. https://doi.org/10.2466/pr0.1997.81.3.963

15.Crocker PR, Eklund RC, Graham TR. Evaluating the factorial structure of the revised causal dimension scale in adolescents. Research Quarterly for Exercise and Sport. 2002;73(2):211-218. https://doi.org/10.1080/02701367.2002.10609011

16.Dong Y, Stupnisky RH, Berry JC. Multiple causal attributions: An investigation of college students learning a foreign language. European Journal of Psychology of Education. 2013;28(4):1587-1602. https://doi.org/10.1007/s10212-013-0183-4

17.Dong Y, Stupnisky RH, Obade M, Gerszewski T, Ruthig JC. Value of college education mediating the predictive effects of causal attributions on academic success. Social Psychology of Education. 2015;18(3):531-546. https://doi.org/10.1007/s11218-015-9299-5

18.Wang H, Hall NC, Rahimi S. Self-efficacy and causal attributions in teachers: Effects on burnout, job satisfaction, illness, and quitting intentions. Teaching and Teacher Education. 2015;47:120-130. https://doi.org/10.1016/j.tate.2014.12.005

19.R Core Team. $R$ : A language and environment for statistical computing. Wienna: R Foundation for Statistical Computing; 2019.

20.Revelle W. Procedures for Personality and Psychological Research. [Internet]. 2019. [updated 2020 Jun 15; cited
2020 Nov 5]. Available from: https://CRAN.R-project.org/ package $=$ psych Version $=1.9 .12 .2019$.

21.Rosseel Y. Lavaan. An R package for structural equation modeling and more. Version 0.5-12 (BETA). Journal of statistical software. 2012;48(2):1-36. https://doi.org/10.18637/jss.v048.i02

22.Kline RB. Principles and practice of structural equation modelling. New York: The Guilford Press; 2011.

23.Satorra A, Bentler PM. A scaled difference chi-square test statistic for moment structure analysis. Psychometrika. 2001;66(4):507-514. https://doi.org/10.1007/BF02296192

24.Steiger JH. Structural model evaluation and modification: An interval estimation approach. Multivariate Behavioral Research. 1990;25(2):173-180. https://doi.org/10.1207/s15327906mbr2502_4

25.Bentler PM. Comparative fit indexes in structural models. Psychological Bulletin. 1990;107(2):238-246. https://doi.org/10.1037/0033-2909.107.2.238

26.Tucker LR, Lewis C. A reliability coefficient for maximum likelihood factor analysis. Psychometrika. 1973;38:1-10. https://doi.org/10.1007/BF02291170

27.Cohen J. A power primer. Psychological Bulletin. 1992;112(1):155-159. https://doi.org/10.1037/0033-2909.112.1.155

28.Brown TA. Confirmatory factor analysis for applied research. New York: Guilford publications; 2015.

29. Cheung GW, Rensvold RB. Evaluating goodnessof-fit indexes for testing measurement invariance. Structural Equation Modeling. 2002;9(2):233-255. https://doi.org/10.1207/S15328007SEM0902_5

30.Dinić B. Principi psihološkog testiranja [Principles of psychological testing]. Novi Sad: Filozofski fakultet Novi Sad; 2019 .

31.Vandenberg RJ, Lance CE. A review and synthesis of the measurement invariance literature: Suggestions, practices, and recommendations for organizational research. Organizational Research Methods. 2000;3(1):4-70. https://doi.org/10.1177/109442810031002

32.Hamilton PR, Jordan SJ. Most Successful and Least Successful Performances: Perceptions of Causal Attributes in High School Track Athletes. Journal of Sport Behavior. 2000;23(3):245-254.

33.Santamaria VL, Furst DM. Distance runners' causal attributions for most successful and least successful races. Journal of Sport Behavior. 1994;17(1):43-51.

34.Tenenbaum G, Furst DM. Consistency of attributional responses by individuals and groups differing in gender, perceived ability and expectations for success. British Journal of Social Psychology. 1986;25(4):315-321. https://doi.org/10.1111/j.2044-8309.1986.tb00743.x

35.De Michele PE, Gansneder B, Solomon GB. Success and failure attributions of wrestlers: Further evidence of the selfserving bias. Journal of Sport Behavior. 1998;8:242-255. 


\section{Information about the authors:}

Rebeka Prosoli; https://orcid.org/0000-0001-6571-6200; rebeka.prosoli@kif.hr; Faculty of Kinesiology, University of Zagreb; Zagreb, Croatia.

Benjamin Banai; https://orcid.org/0000-0002-2249-5257; ben@predikt.hr; Banai Analitika; Zagreb, Croatia.

Renata Barić; https://orcid.org/0000-0003-2614-673X; renata.baric@kif.hr; Faculty of Kinesiology, University of Zagreb; Zagreb, Croatia.

Marc Lochbaum; (Corresponding author); https://orcid.org/0000-0001-7640-7075; marc.lochbaum@ttu.edu; Department of Kinesiology and Sport Management, Texas Tech University, USA; Education Academy, Vytautas Magnus University, Lithuania.

Sydney Cooper; https://orcid.org/0000-0001-6610-5444; sydneyco@ttu.edu; Honors College, Texas Tech University; USA.

Margareta Jelić; https://orcid.org/0000-0002-2478-0756; mjelic@ffzg.hr; Faculty of Humanities and Social Sciences, University of Zagreb; Zagreb, Croatia.

Cite this article as:

Prosoli R., Banai B, Barić R, Lochbaum M, Cooper S, Jelić M. Causal attributions for success and failure among athletes: Validation of the Croatian version of the revised Causal dimension scale (CDS-II). Pedagogy of Physical Culture and Sports, 2021;25(4):244-252.

https://doi.org/10.15561/26649837.2021.0406

This is an Open Access article distributed under the terms of the Creative Commons Attribution License, which permits unrestricted use, distribution, and reproduction in any medium, provided the original work is properly cited (http://creativecommons.org/licenses/by/4.0/deed.en).

Received: 15.04 .2021

Accepted: 01.06.2021; Published: 30.08.2021 